\title{
ANATOMICAL AND BEHAVIORAL RECOVERY FROM THE EFFECTS OF SPINAL CORD TRANSECTION: DEPENDENCE ON METAMORPHOSIS IN ANURAN LARVAE ${ }^{1}$
}

\author{
CYNTHIA J. FOREHAND ${ }^{2}$ AND PAUL B. FAREL ${ }^{3}$ \\ Neurobiology Program and Department of Physiology, School of Medicine, University of North Carolina, Chapel Hill, North \\ Carolina 27514
}

Received October 29, 1981; Revised December 23, 1981; Accepted December 30, 1981

\begin{abstract}
This study of spinal cord injury in bullfrog (Rana catesbeiana) tadpoles using the neuroanatomical tracer horseradish peroxidase (HRP) was undertaken to determine (1) whether the same anatomical regions that normally give rise to ascending or descending spinal tracts do so following complete spinal cord transection and (2) whether the course of behavioral recovery could be related to the anatomical results. The results of this study show that (1) spinal cord continuity is readily restored in tadpoles subjected to spinal cord transection, but nerve fibers crossing the site of injury end within 1 to $2 \mathrm{~mm}$ of the lesion site; (2) tadpoles with spinal cord transections held through metamorphosis show, as juvenile frogs, restoration of lumbar projections from all brainstem regions that normally project to the lumbar spinal cord; (3) neither long ascending projections from dorsal root ganglion cells nor those from spinal neurons caudal to the transection traverse the transection site, even after metamorphosis; and (4) consistent with the anatomical results, tadpoles show only minimal behavioral recovery, but these same animals as juvenile frogs show recovery of behaviors that are dependent upon connections to supraspinal regions.

In other experiments, $\left[{ }^{3} \mathrm{H}\right]$ thymidine or $\left[{ }^{3} \mathrm{H}\right]$ apo-HRP was combined with $\mathrm{HRP}$ histochemistry to determine if new brainstem neurons projecting to the spinal cord are born in the metamorphic period and if, in normal animals, brainstem projections to the lumbar spinal cord persist through metamorphosis. We found no evidence that neurons with lumbar spinal cord projections are born during metamorphosis; however, evidence was found that most brainstem neurons that project to the lumbar spinal cord before metamorphosis retain this projection in the juvenile frog.
\end{abstract}

Transection of the mammalian spinal cord results in permanent loss of anatomical continuity between the severed halves, and behavioral recovery is limited to the return of spinal reflexes (Puchala and Windle, 1977). In contrast, restoration of anatomical continuity and behavioral recovery have been found in cold-blooded vertebrates, such as lamprey (Rovainen, 1976; Selzer, 1978;

\footnotetext{
${ }^{1}$ We wish to thank Carol Metz and Marie Lancaster for very able histological assistance and Sibyl Bemelmans for help in figure preparation. This work was supported by Public Health Service Grants NS16030 and NS14899. This work forms part of a dissertation submitted in partial fulfillment of the requirements for the degree, Doctor of Philosophy in Neurobiology (C. J. F.).

${ }^{2}$ Present address: Department of Physiology and Biophysics, Washington University Medical School, $660 \mathrm{~S}$. Euclid Avenue, St. Louis, MO 63110.

${ }^{3}$ To whom correspondence should be addressed at Department of Physiology-206H, University of North Carolina School of Medicine, Chapel Hill, NC 27514.
}

Wood and Cohen, 1981), fish (Hooker, 1932; Tuge and Hanzawa, 1937; Bernstein and Gelderd, 1970, 1973), urodele amphibia (Holtzer, 1952; Piatt, 1955), and larval anuran amphibia (Hooker, 1925; Michel and Reier, 1979). However, anatomical continuity is not restored following spinal cord transection in adult anurans (Piatt and Piatt, 1958; Afelt, 1963; Farel, 1971).

Although restoration of anatomical continuity following spinal cord transection is amply documented in coldblooded vertebrates, whether previously transected ascending and descending fibers regain their preoperative patterns of connectivity has not been fully investigated. The anterograde labeling of reticulospinal fibers in the regenerated spinal cord of larval lamprey (Selzer, 1978; Wood and Cohen, 1979, 1981) provides the only direct evidence concerning the source of regenerated fibers.

The present study of recovery following spinal cord transection in anuran larvae was undertaken to determine (1) whether the same anatomical regions that normally give rise to ascending or descending spinal tracts 
do so following spinal cord transection and (2) whether the course of behavioral recovery could be related to the anatomical results. The bullfrog (Rana catesbeiana) tadpole was chosen because its large size allows the ready use of neuroanatomical tracers and because its behavioral repertoire after metamorphosis is considerably greater than that of the other cold-blooded vertebrates studied, allowing better assessment of the effects of transection and recovery. Further, the 2- to 3-year span of bullfrog larval development (Dickerson, 1969) means that temporally spaced procedures can be performed on the same animal with little intervening development.

\section{Materials and Methods}

Bullfrog (Rana catesbeiana) tadpoles were obtained from Carolina Biological Supply (Burlington, NC) and maintained in conventional aquaria. The animals were staged according to the criteria of Taylor and Kollros (1946). According to this scheme, tadpoles are staged primarily on the basis of hindlimb morphology, beginning with the onset of independent feeding at stage I. Stages I to $\mathrm{V}$ are limb bud stages, while foot paddle stages extend from VI to X. During stages XI to XVII, the premetamorphic stages, the hindlimb becomes progressively larger and is of more use to the animal for swimming and pushing against obstacles. Stages XVIII to $\mathrm{XXV}$, the metamorphic stages, begin with degeneration of the cloacal tailpiece. The forelimbs emerge at stage $\mathrm{XX}$ (climax), and the tail undergoes progressive degeneration until it is resorbed completely at stage XXV.

Surgery. Midthoracic spinal cord transections were performed on tadpoles of all stages through an opening in the cartilage of the dorsal vertebral arches under cold anesthesia. Transection at this level avoids damage to fore- and hindlimb motoneurons of the brachial and lumbar lateral motor columns. Only those animals were used in which the two halves of the spinal cord separated, exposing the floor of the vertebral canal and thus providing assurance that the transection was complete. Following surgery, tadpoles were kept in bins containing 2 liters of conditioned water ( $\mathrm{pH} 6.7$ to 7.2 ), $75 \%$ of which was changed on alternate days, until metamorphosis. At this time, the animals were placed in covered Petri dishes containing wet gauze to avoid drowning. The room in which the animals were kept was maintained at $24^{\circ} \mathrm{C}$ and illuminated $16 \mathrm{hr}$ a day.

Horseradish peroxidase application and histological procedures. For horseradish peroxidase (HRP; Sigma, Type VI) application, animals were anesthetized by immersion in $0.02 \%$ tricaine methanesulfonate (Sigma) in frog Ringer solution. A 00 insect pin coated with recrystallized HRP was inserted into the exposed spinal cord and held in place until the HRP dissolved. Retrogradely labeled brainstem neurons were visualized using the Hanker-Yates substrate (Hanker et al., 1977) as previously described (Farel and Bemelmans, 1980). The HRP was histochemically demonstrable following survival periods of 3 to $40 \mathrm{~d}$.

Some tadpoles that had received lumbar HRP applications were, after metamorphosis, given a lumbar injection of a second retrograde tracer: tritiated, enzymatically inactive HRP ( $\left[{ }^{3} \mathrm{H}\right]$ apo-HRP; New England Nuclear).
Using a glass pipette with a $15-\mu \mathrm{m}$ tip diameter attached to a microsyringe, $0.05 \mu \mathrm{l}$ of a 10 to $20 \mu \mathrm{Ci} / \mu \mathrm{l}$ solution of $\left[{ }^{3} \mathrm{H}\right]$ apo-HRP in distilled water was injected into the lumbar enlargement. Following a survival period of $3 \mathrm{~d}$, 15- $\mu \mathrm{m}$ frozen sections were processed for HRP histochemistry and mounted on slides, and conventional autoradiographic techniques were applied (Cowan et al., 1972). Slides were developed for $2^{1 / 2}$ min after an exposure time of 8 weeks.

In other experiments, tadpoles were injected intraperitoneally with a total of $30 \mu \mathrm{l}$ of a $10 \mu \mathrm{Ci} / \mu \mathrm{l}$ solution of $\left[{ }^{3} \mathrm{H}\right]$ thymidine in distilled water on three occasions $3 \mathrm{~d}$ apart, and the same histological procedures as above were followed except a 6-week exposure was followed by a 2-min development time. These procedures allow colorimetric visualization of the HRP and the observation of the tritium label (indicating the presence of $\left[{ }^{3} \mathrm{H}\right]$ apoHRP or $\left[{ }^{3} \mathrm{H}\right]$ thymidine) as reduced silver grains in the emulsion overlying the labeled cells.

\section{Results}

\section{Transection without metamorphosis}

Behavior. Immediately following a midthoracic transection, tadpoles of any stage were immobile and lay on their sides. Spinal reflexes caudal to the transection could be readily elicited. Normal body position usually was regained in 1 to $2 \mathrm{~d}$. Short episodes of swimming in response to visual or tactile stimuli were observed beginning 10 to $15 \mathrm{~d}$ after transection, although activation of swimming musculature was restricted initially to the side of the transection to which the stimulus was applied. Spinal tadpoles also swam in the absence of overt stimulation. Righting reflexes, when present, were sluggish and did not appear to involve body regions below the transection. These behavioral deficits were still present in tadpoles $90 \mathrm{~d}$ after transection, the longest postoperative period examined.

No clear or consistent evidence was found that rostral control of body regions below the level of the transection had returned. Tadpoles, which at autopsy were found to lack spinal cord continuity, showed behavioral changes indistinguishable from those of animals in which spinal cord continuity was restored. Thus, the post-transectional changes in behavior described above do not appear to depend on restoration of spinal cord pathways.

Anatomy. Gross anatomical continuity between the severed ends of the spinal cord usually was restored within 2 weeks of transection. At this time, sufficient tissue bridged the transection site that, at sacrifice, the isolated spinal cord could be suspended by one end without tearing the cord at the lesion site. HRP was applied to the lumbar spinal cord of 15 tadpoles ranging from stages VI to XVII following spinal cord transection 23 to $90 \mathrm{~d}$ previously $(\bar{x}=67 \mathrm{~d})$. In contrast to the heavy labeling of fibers through the thoracic region found in normal tadpoles (Fig. 1a), tadpoles previously subjected to midthoracic spinal cord transection showed no evidence of HRP-labeled fibers crossing the reconstituted transection site (Fig. 1b). At higher magnification (Fig. 1c), fibers can be seen to approach the transection site and turn abruptly in a manner which has long been associated with the abortive attempts at spinal cord 

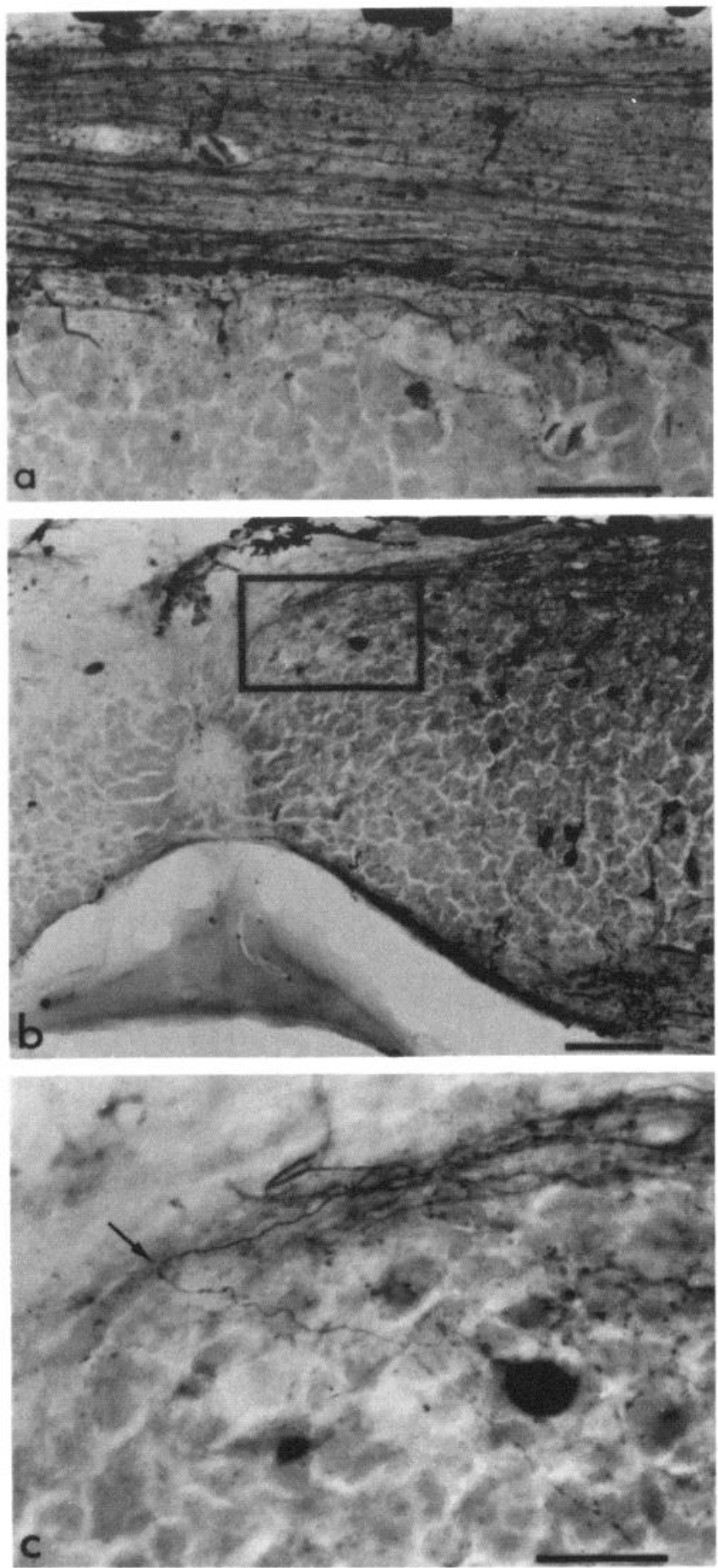

Figure 1. Horizontal sections through the thoracic spinal cord following lumbar HRP application. Rostral is to the left. $a$, Normal stage IV tadpole showing typical heavy labeling of fibers in the lateral funiculus. Calibration bar, $50 \mu \mathrm{m}$. $b$, Stage $\mathrm{X}$ tadpole labeled with HRP $30 \mathrm{~d}$ following midthoracic transection. Labeled fibers approach the transection site but do not traverse the reconstituted zone. Calibration bar, $100 \mu \mathrm{m}$. $c$, Higher magnification micrograph of the area enclosed by the rectangle in $b$. Fiber (arrow) turns abruptly as it approaches the transection site. Calibration bar, $30 \mu \mathrm{m}$.

regeneration in mammals (Ramon y Cajal, 1959). Similarly arcing fibers rostral to the transection are labeled when HRP is placed in the brachial enlargement or brainstem. In 12 of 15 tadpoles receiving lumbar appli- cation of HRP, no retrogradely labeled cells were observed rostral to the transection site. The brainstems of 3 of the 15 tadpoles were found to contain, respectively, one, two, and four labeled neuronal somata. This limited anatomical recovery was not related to postoperative survival time, developmental stage at transection, or degree of behavioral recovery.

Although neuronal elements bridging the transection site were only rarely labeled following lumbar application of HRP, cells on the opposite side of the transection site could be readily labeled by $H R P$ placed within $2 \mathrm{~mm}$ (one segment) of the reconstituted zone (Fig. 2). The possibility that these cells were labeled by diffusion of the HRP across the transection site cannot be ruled out, but the fact that more distant neurons were not labeled mitigates against this possibility. The labeled cells were 5 to $15 \mu \mathrm{m}$, roughly spherical or ovoid, and possessed one or two processes. The usual, but not invariable, location of these cells outside of the ependymal zone argues
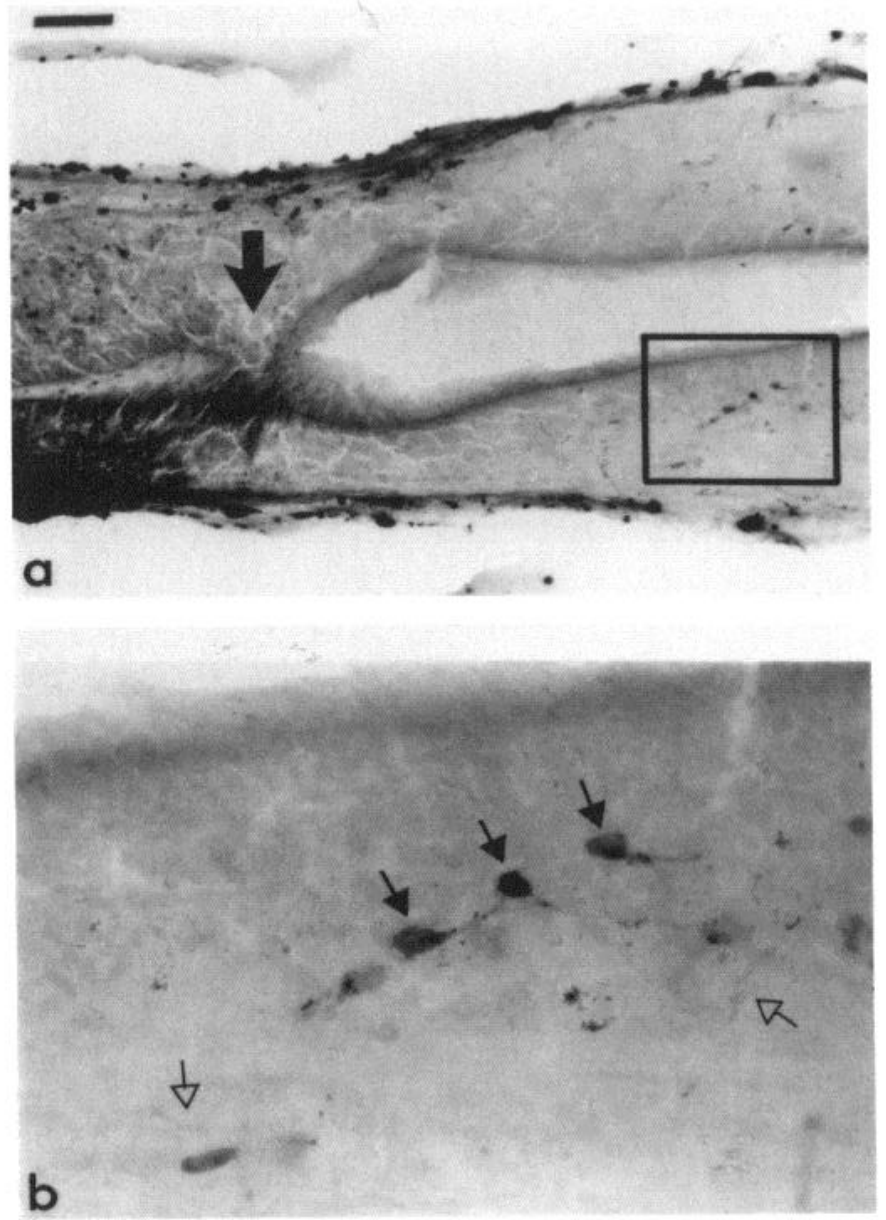

Figure 2. $a$, Horizontal section through the thoracic spinal cord from a stage IX tadpole whose spinal cord was transected $40 \mathrm{~d}$ previously. HRP was applied to the lumbar enlargement $3 \mathrm{~d}$ previously. Rostral is to the right. Most labeled fibers do not traverse the transection site (arrow), but a few labeled cell bodies (rectangle) can be seen within $1 \mathrm{~mm}$ of the transection site. Calibration bar, $100 \mu \mathrm{m}$. $b$, Higher power micrograph of the area enclosed by the rectangle in $a$ showing HRP-labeled fibers (open arrows) and cell bodies (solid arrows) rostral to the transection site. Calibration bar, $25 \mu \mathrm{m}$. The calibration $b a r$ in $a$ applies to $a$ and $b$. 
against their being radial glia, which can be labeled with HRP in the tadpole (Chu-Wang et al., 1981). Final identification of these cells must await further investigation.

HRP placed just rostral to the transection site, in addition to labeling cells in the segment caudal to the lesion, also labeled brainstem neurons in all supraspinal regions that give rise to spinal projections in normal tadpoles (Forehand and Farel, 1981). This finding provides assurance that the failure of the long descending tracts to regenerate was not due to the death of the projecting neurons following transection.

\section{Transection followed by metamorphosis}

Behavior. In contrast to the results obtained from transected animals observed as tadpoles, 17 of 22 animals that underwent spinal transection as tadpoles (stages XVII to XIX) showed substantial behavioral recovery after metamorphosis. Postoperative survival times for these animals ranged from $18 \mathrm{~d}$ to 10 months $(\bar{x}=75 \mathrm{~d})$. These juvenile frogs had vigorous righting reflexes, swam readily in a normal fashion when immersed in water, and reacted in a coordinated manner to visual stimuli. Two of these 17 animals were indistinguishable from normal juveniles according to these criteria. The remaining 15 frogs retained some deficits in movement and posture, at least partially resulting from damage to the lateral motor columns by too caudal placement of the initial transection.

Five of the 22 juvenile frogs transected as tadpoles showed no behavioral recovery and had severe skeletal abnormalities (possibly the result of damage to the notochord during transection) with minimal or absent spinal cord continuity. Tadpoles operated before stage XVI did not complete metamorphosis even after months of postoperative survival. Tadpoles that underwent spinal cord transection after metamorphic climax (stage $\mathrm{XX}$ ) showed no evidence of behavioral or anatomical recovery as juvenile frogs, a result similar to that seen when transection is performed in adult bullfrogs (Farel, 1971). These animals manifested no rostral control over body areas caudal to the transection site; righting and attempts at swimming involved only the forelimbs. The best results were obtained when spinal cord transections were performed at stages XVII to XVIII.

Anatomy. The most striking anatomical correlate of the behavioral recovery seen in frogs that had undergone spinal cord transection as tadpoles was the return of brainstem projections to the lumbar spinal cord. Four of these experimental frogs were examined for the return of long tracts by lumbar application of HRP. In each of these animals, despite considerable constriction of the spinal cord at the lesion site (Fig. 3), retrogradely labeled fibers traversed the transection site, and the brainstem neurons of origin could be identified (Fig. 4). A comparison of the number and location of labeled brainstem neurons between a normal and an experimental juvenile frog is shown in Figure 5. Retrogradely labeled neurons in all brainstem regions found in the normal animal (e.g., paraventricular area of the hypothalamus, vestibular nucleus, reticular formation, and raphe area) also are seen in the frog which had undergone spinal cord transection as a tadpole. However, fewer neurons were labeled retrogradely in experimental than in normal frogs. In the 4

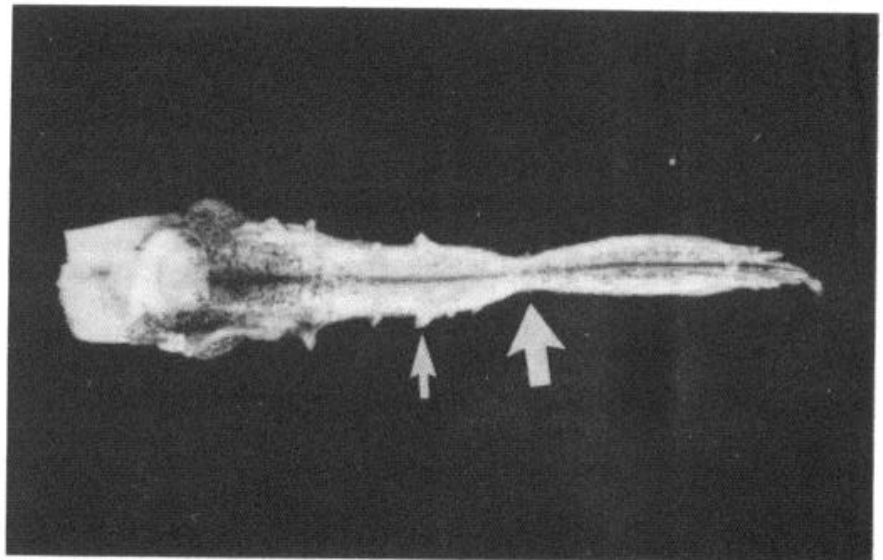

Figure 3. Gross specimen of frog spinal cord 6 months after metamorphosis and 8 months after spinal cord transection as a stage XVII tadpole. In this ventral view, the midthoracic transection site (large arrow) is still prominent. The third ventral root, providing innervation to the forelimbs, is marked by the small arrow. Magnification $\times 4$.
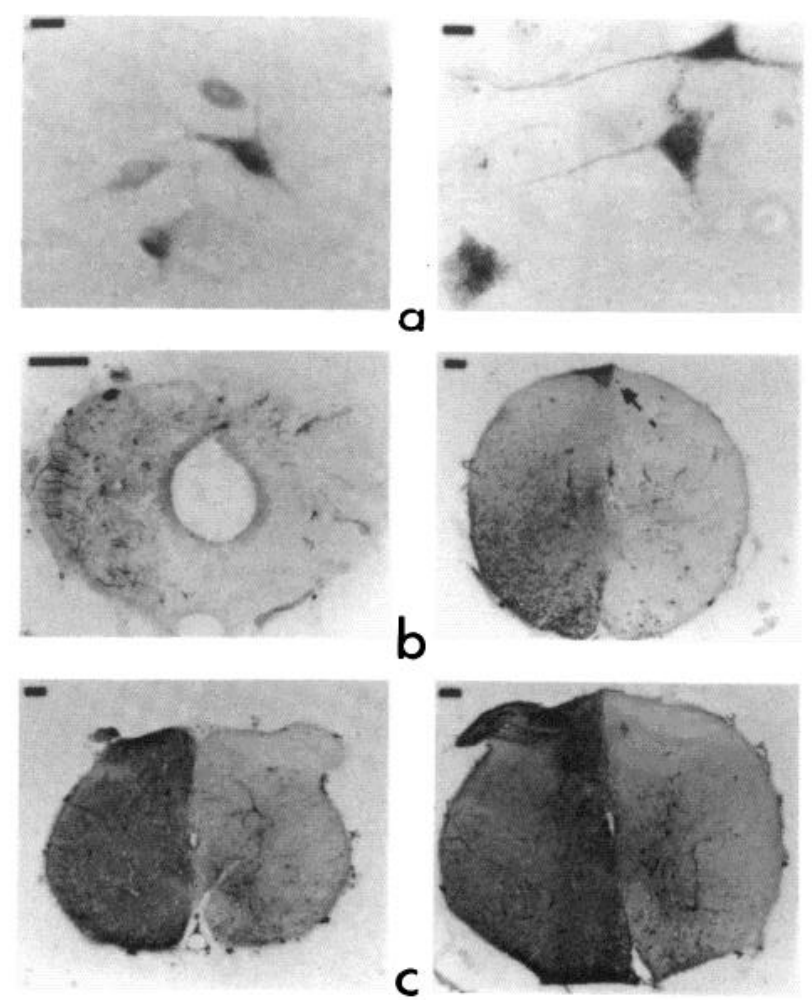

Figure 4. Comparison of neurons labeled by lumbar HRP application in an experimental frog (left, same animal shown in Fig. 3) and an unoperated control (right). $a$, Labeled neurons in the vestibular nucleus ipsilateral to HRP application. Calibration bars, $10 \mu \mathrm{m}$. $b$, Fiber labeling in the thoracic spinal cord. The dorsal column pathway is present only in the normal animal (arrow). In addition to being considerably smaller (note calibration bars), the cord from the operated animal shows fewer labeled fibers. Calibration bars, $100 \mu \mathrm{m}$. $c$, Sections just rostral to the site of HRP application in the lumbar spinal cord. Calibration bars, $100 \mu \mathrm{m}$.

frogs examined, the numbers of retrogradely labeled brainstem neurons were $73,93,124$, and 516 . The number of retrogradely labeled neurons in experimental frogs was not related to the stage at which the spinal cord was 

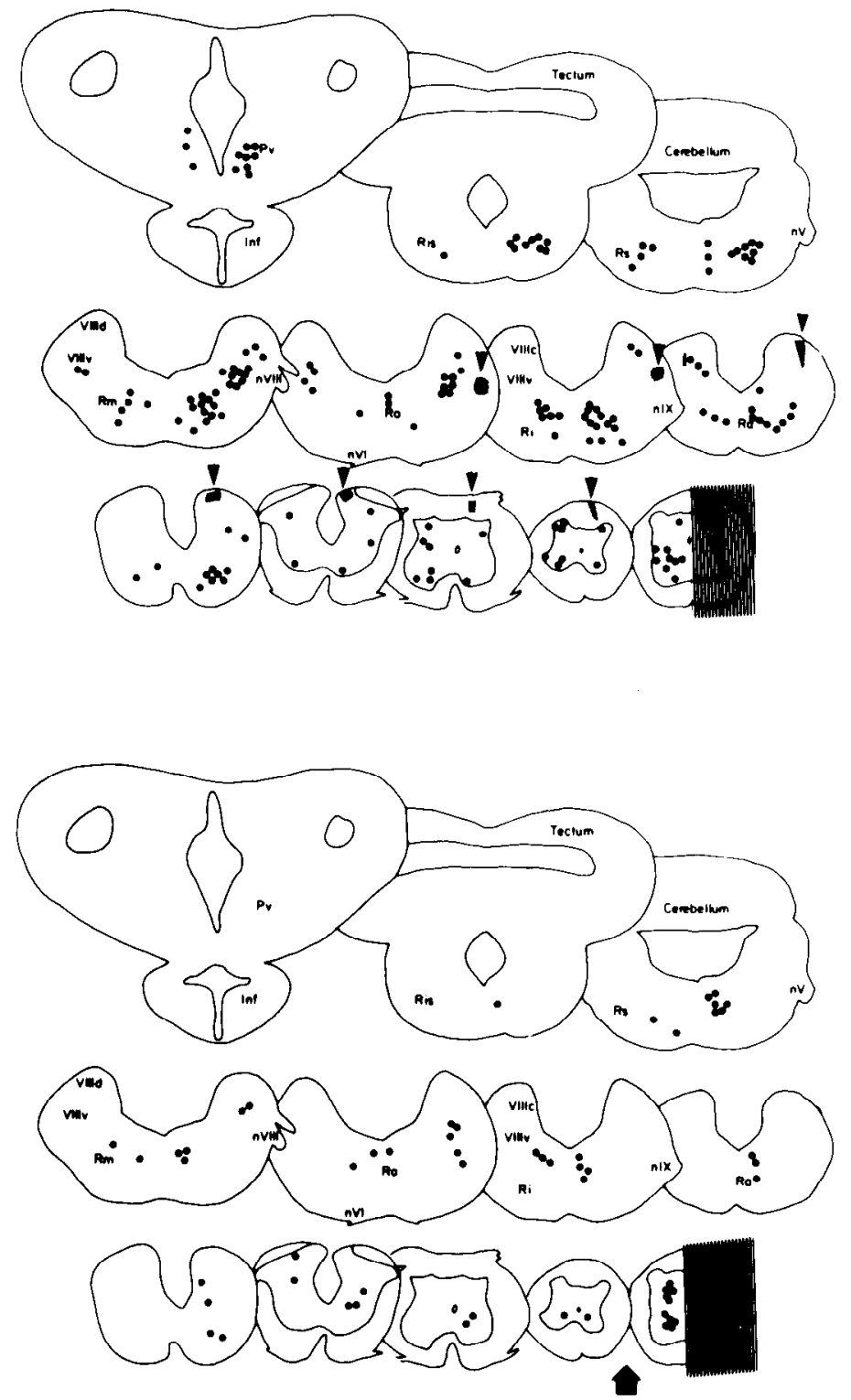

Figure 5. Locations of brainstem neurons retrogradely labeled by a lumbar HRP application in a normal juvenile frog (top) and in a juvenile frog that had undergone spinal cord transection as a tadpole (bottom). Cells were plotted from three alternate $40-\mu \mathrm{m}$ sections through the indicated region. The dorsal column fiber pathway (arrowheads) is absent rostral to the transection site (large arrow) in the experimental frog. HRP application sites are indicated by shading. The sections are not drawn to scale between the animals. The abbreviations used are: $I n f$, infundibulum; $n V$ to $n I X$, cranial nerves $V$ to IX; $P v$, paraventricular nucleus of the hypothalamus; $R a$, raphe nucleus; $R i$, nucleus reticularis inferior; $R i s$, nucleus reticularis isthmi; $R m$, nucleus reticularis medial; $R s$, nucleus reticularis superior; VIIIc, caudal nucleus of the VIIIth nerve; VIIId, dorsal nucleus of the VIIIth nerve; VIIIv, ventral (vestibular) nucleus of the VIIIth nerve.

transected, postoperative survival time, or extent of behavioral recovery. These totals can be compared to counts of 875 and 837 obtained, respectively, from a control juvenile frog following lumbar application of HRP and from a juvenile frog transected as a tadpole in which the HRP was placed immediately rostral to the lesion site. The large number of labeled neurons in this latter frog provides evidence that spinal cord transection does not reduce substantially the number of brainstem neurons projecting at least as far as the transection site.

Although all supraspinal areas projecting to the lumbar spinal cord in normal frogs and tadpoles also projected to the lumbar cord in juveniles which had undergone spinal cord transection as tadpoles, ascending projections of either spinal or primary afferent origin were not observed. Primary afferent fibers in the dorsal funiculus anterogradely labeled by lumbar HRP application in normal frogs (Fig. $4 b$, arrow) were not seen above the level of the transection in previously operated frogs, although retrogradely labeled dorsal root ganglion cells and spinal neurons were seen. Similarly, in 2 juvenile frogs, spinal neurons caudal to the lesion site, which normally give rise to brainstem projections, were not labeled retrogradely by IIRP applied to the spinal cord rostral to the level of a spinal cord transection performed in larval stages. Orthogradely labeled fibers crossing the lesion site were seen following these rostral HRP applications.

Tadpoles held as long as 3 months showed no further recovery beyond that evident within the 1st postoperative month. However, both anatomical and behavioral recovery were apparent in animals that metamorphosed within $18 \mathrm{~d}$ of spinal cord transection. These observations lead to the conclusion that re-establishment of long pathways following spinal cord transection depends on developmental processes within the metamorphosing tadpole rather than time per se. The question, whether restoration of descending connections represents regeneration of previously transected fibers or development of new pathways, was addressed by combining the HRP procedure with $\left[{ }^{3} \mathrm{H}\right]$ thymidine or $\left[{ }^{3} \mathrm{H}\right]$ apo-HRP.

\section{Double label studies}

$\left[{ }^{3} H\right]$ Thymidine and HRP. To determine if newly born neurons contribute to the re-establishment of long tracts in transected spinal cords at metamorphosis, 1 stage XVIII and 2 stage XVII tadpoles each were given a total of $30 \mu \mathrm{Ci}$ of $\left[{ }^{3} \mathrm{H}\right]$ thymidine in three injections $3 \mathrm{~d}$ apart. These animals were allowed to metamorphose, and HRP was applied to the lumbar spinal cord of the juvenile frogs. Figure 6 demonstrates the presence of $\left[{ }^{3} \mathrm{H}\right]$ thymidine-labeled cells and HRP-labeled neurons in the vestibular nucleus of a juvenile frog. Numerous cells containing either $\left[{ }^{3} \mathrm{H}\right]$ thymidine or HRP were observed; however, no cells in the brainstem containing both labels were found. Most of the $\left[{ }^{3} \mathrm{H}\right]$ thymidine-labeled cells appeared to be non-neuronal. If neuronal proliferation does occur during late larval stages, neurons projecting to the spinal cord could not be identified as part of the proliferative pool.

HRP and $\left[{ }^{3} \mathrm{H}\right]$ apo-HRP studies. If regeneration is occurring, one would expect that, in normal animals, brainstem connections to the lumbar spinal cord would be maintained through metamorphosis. To test this point, HRP was applied to the lumbar enlargements of 4 stage XVII tadpoles. Preliminary studies (Forehand and Farel, 1981) had shown that the HRP reaction product could still be visualized $40 \mathrm{~d}$ after application, suffi- 


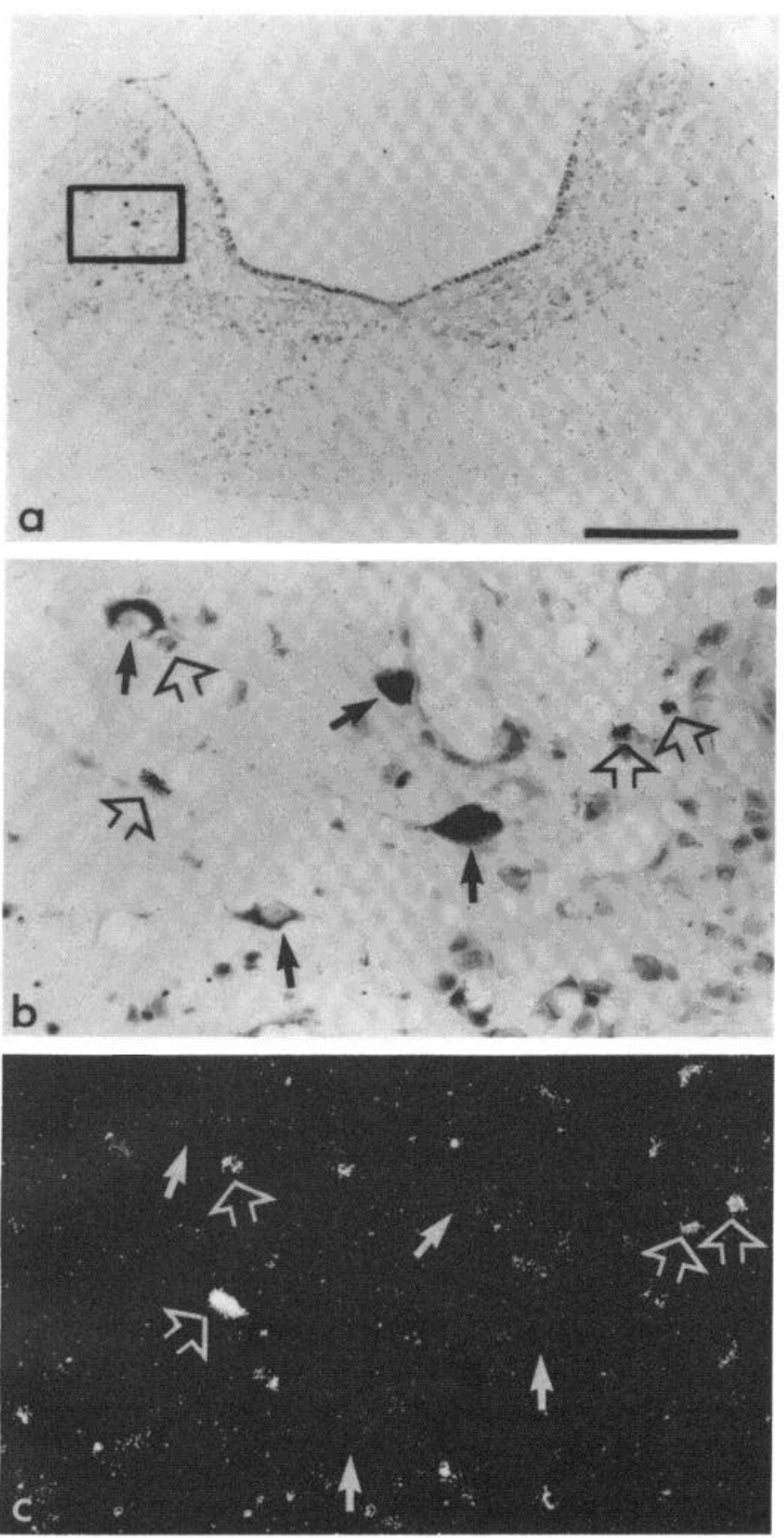

Figure 6. To test for the possibility that neurons born in late larval stages give rise to lumbar projections, $\left[{ }^{3} \mathrm{H}\right]$ thymidine was given to a stage XVII tadpole and, after metamorphosis, HRP was applied to the lumbar enlargement. $a$, Low power micrograph of brainstem. The rectangle encompasses the vestibular nucleus. Calibration bar, $300 \mu \mathrm{m}$. $b$, Higher power view of cells in vestibular nucleus containing either $\left[{ }^{3} \mathrm{H}\right]$ thymidine (open arrows) or HRP (solid arrows). No doubly labeled cells were found. Calibration bar, $50 \mu \mathrm{m}$. $c$, As in $b$ but in dark-field. The calibration bar in $a$ applies to $a, b$, and $c$.

cient time for the operated tadpoles to complete metamorphosis. Following metamorphosis, $\left[{ }^{3} \mathrm{H}\right]$ apo-HRP was injected into the lumbar spinal cords of the now juvenile frogs and the brainstems were processed for HRP histochemistry and tritium autoradiography. Neurons that contained both HRP and $\left[{ }^{3} \mathrm{H}\right]$ apo-HRP were identified unambiguously in the brainstem reticular formation, vestibular nucleus, and rostral spinal cord (Fig. 7). Many neurons contained only $\left[{ }^{3} \mathrm{H}\right]$ apo-HRP, an unsurprising result because the HRP label does diminish with long survival periods. However, most neurons in which HRP could still be demonstrated histochemically also contained $\left[{ }^{3} \mathrm{H}\right]$ apo-HRP, indicating that these neurons project to the lumbar spinal cord in the tadpole and retain this projection through metamorphosis in normal animals. Whether brainstem neurons containing only $\left[{ }^{3} \mathrm{H}\right]$ apo-HRP might have developed lumbar projections after application of the first label cannot be evaluated at this time.

The clearest way to demonstrate true regeneration of descending connections would be to label retrogradely brainstem neurons projecting to the lumbar spinal cord with HRP, transect the spinal cord, allow the animal to metamorphose, and then apply $\left[{ }^{3} \mathrm{H}\right]$ apo-HRP to the lumbar enlargement. The presence of doubly labeled neurons in this experiment would demonstrate true regeneration of descending connections. Unfortunately, as in Xenopus (Sims, 1962), the mortality rate among metamorphosing, transected larvae is very high, and no animals survived the double labeling of brainstem neurons combined with spinal cord transection and metamorphosis.

\section{Discussion}

Tadpoles, regardless of developmental stage, show only limited behavioral and anatomical recovery from the effects of spinal cord transection. After metamorphosis, however, juvenile frogs which had undergone spinal cord transection as tadpoles manifest obvious rostral control over caudal body regions. Correlated with this behavioral recovery, the lumbar spinal cord projections of brainstem neurons can again be demonstrated. This anatomical recovery at metamorphosis represents, to our knowledge, the first demonstration of restoration of brainstem projections to spinal cord segments substantially caudal to the site of transection.

Recovery in tadpoles. The minimal behavioral recovery found in spinal tadpoles contrasts with earlier reports of substantial recovery following transection (e.g., Hooker, 1925). However, behavioral recovery in these studies usually was assessed by observations of swimming. The presence of swimming in the tadpole (Stehouwer and Farel, 1980, 1981), as in the dogfish (Grillner, 1974) and lamprey (Cohen and Wallen, 1980), does not depend on spinal cord connections to higher centers.

The failure of brainstem projections to the lumbar spinal cord to reappear following spinal cord transection is consistent with previous studies using cold-blooded vertebrates. In the lamprey, reticulospinal fibers terminate 1 to $2 \mathrm{~mm}$ caudal to the site of a previous transection (Selzer, 1978; Wood and Cohen, 1979, 1981), even when the rate of regeneration is accelerated by the application of electric currents (Borgens et al., 1981). Restoration of long tracts does occur following spinal cord transection in goldfish. Bernstein and Gelderd (1970), by transecting the spinal cord one segment rostral to the site of a previous transection, were able to show in degeneration material that neurons rostral to the initial site of tran- 

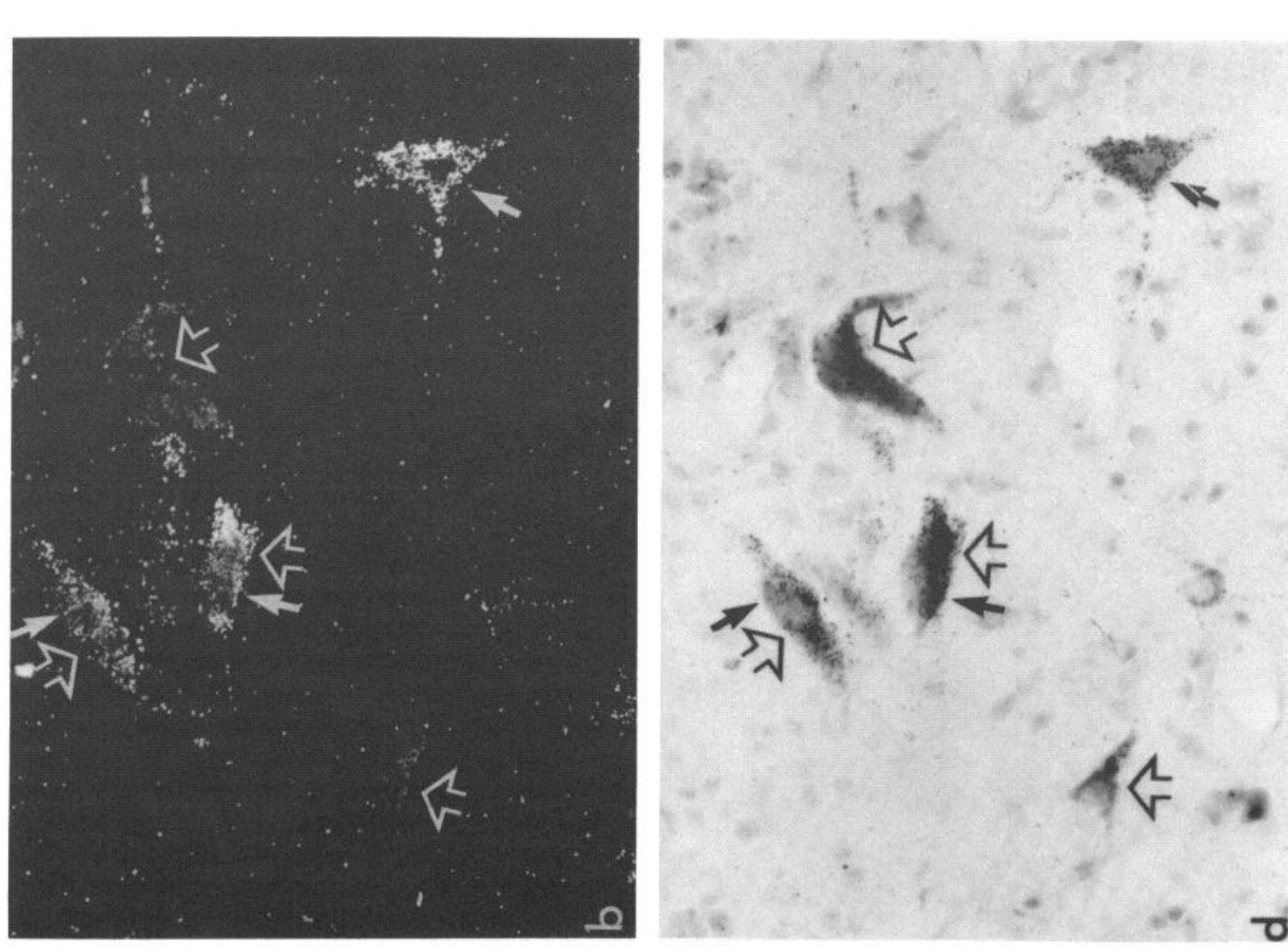

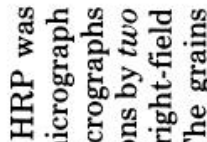
ด 屯ัँ

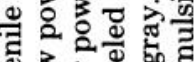

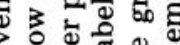

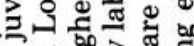
๑ 0 .

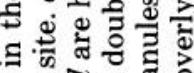
ㄷำ

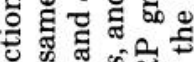

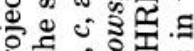
ถึ่ ปี : สำ

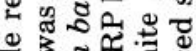

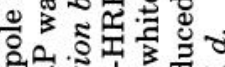

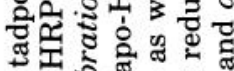

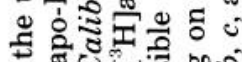

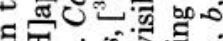

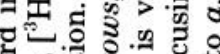
. कै है क्ष

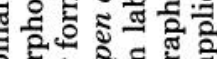

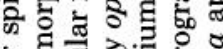
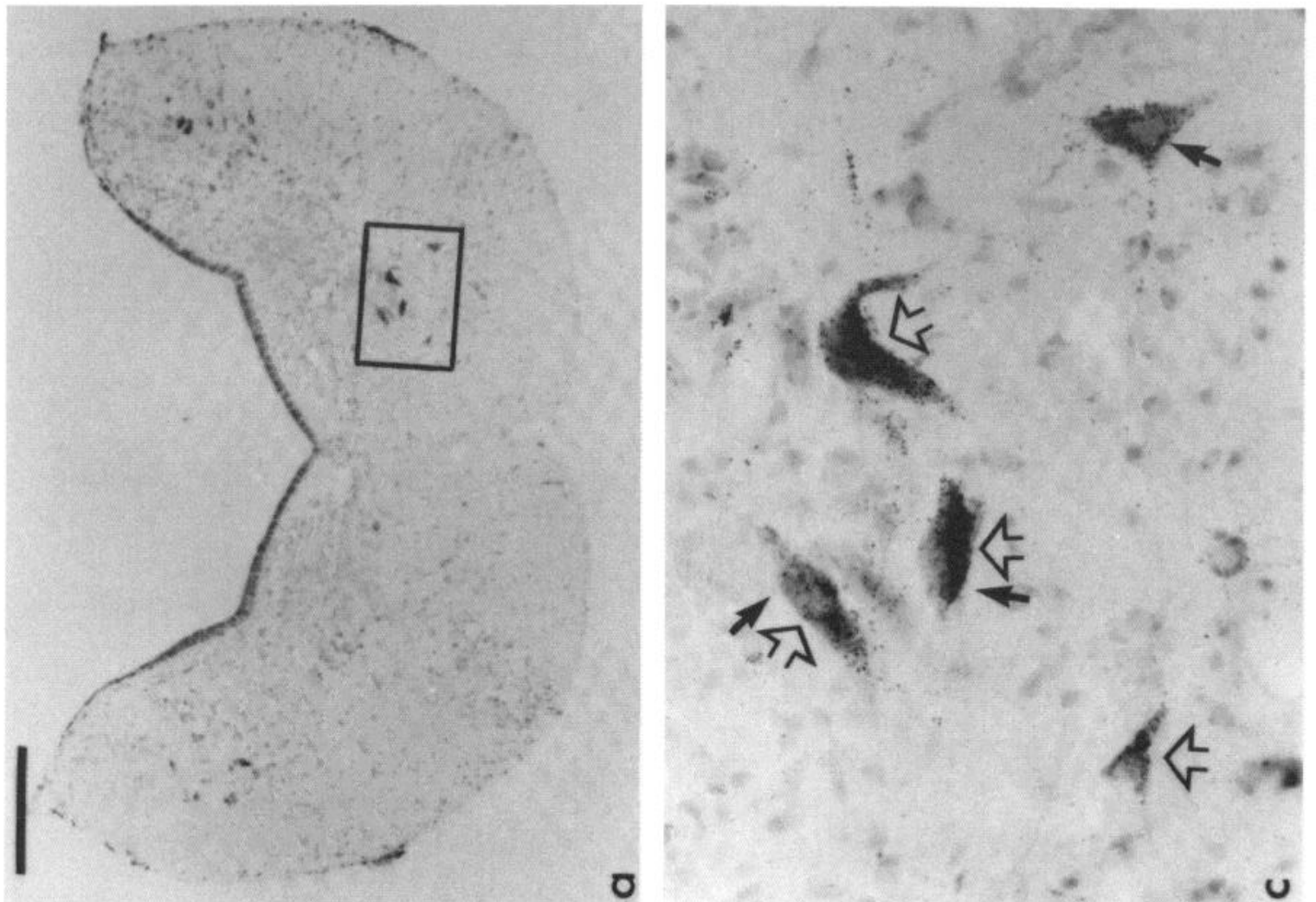

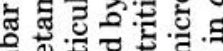

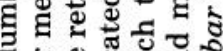
离造造 ๘.

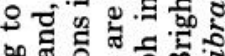

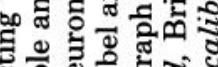
웡

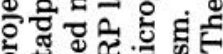

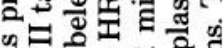

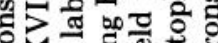

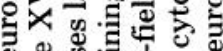
ฐั घ 용

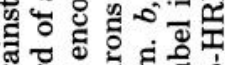

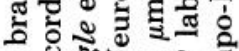

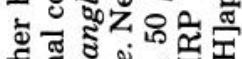

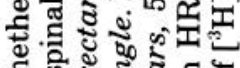
का

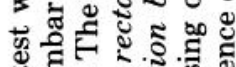

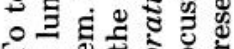
-

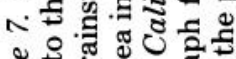
过步

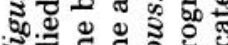

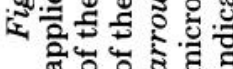


section send axons at least $2 \mathrm{~cm}$ caudal to the initial lesion. However, the location of cell bodies giving rise to these projections was not determined.

Recovery after metamorphosis. Juvenile frogs, which, as spinal tadpoles, had not shown clear evidence of behavioral recovery mediated by supraspinal regions, were responsive to visual stimuli, showed vigorous righting reflexes, and used the fore- and hindlimbs in a coordinated manner during both walking and swimming. Coordinated swimming is a particularly good test of functional recovery because the deficit is easily visible and animals undergoing spinal cord transection as frogs never recover this ability (Afelt, 1963; Farel, 1971). While some behavioral deficit probably would be detected using more precise testing procedures than those employed here, the point should be emphasized that, when the transection was sufficiently rostral to avoid damage to the lateral motor columns, routine observation and handling revealed no behavioral deficit in frogs that had undergone spinal cord transection as tadpoles.

Projections to the lumbar spinal cord arise from the same brainstem regions in normal and experimental frogs. Both indoleaminergic projections from the raphe and catecholaminergic projections from the reticular formation (Soller, 1977) apparently are restored as evidenced by retrograde labeling in both of these areas. No difference in the size or shape of labeled brainstem neurons was evident between normal and experimental frogs. Orthograde labeling of ascending primary afferent axons was not seen in experimental frogs following lumbar HRP application, and projections through the transection site of spinal cord neurons caudal to the injury were also lacking, although both cell types could be labeled by HRP application caudal to the transection site. The reason why ascending projections are lacking is not apparent. Ontogenetically, ascending projections from most spinal neurons arise later than descending projections from the brainstem and are thus less mature at the time of transection (Forehand and Farel, 1980). Another difference between ascending and descending projections is that the axons of spinal neurons are transected closer to their cell bodies than are the axons of brainstem neurons, which may result in differences in the severity of the response to injury (Lieberman, 1971). However, ascending dorsal root projections are also absent in experimental frogs, even though some dorsal root projections are present as early as descending pathways (Forehand and Farel, 1981), and the cells of origin can be farther from the midthoracic transection site than the cells giving rise to descending projections.

The finding that tadpoles surviving $90 \mathrm{~d}$ after spinal cord transection showed no substantial recovery while tadpoles that completed metamorphosis within $18 \mathrm{~d} \mathrm{im}$ proved considerably provides evidence that recovery depends upon processes occurring during the metamorphic period. One possible explanation for the restoration of descending fibers is that brainstem neurons that did not project to the lumbar enlargement at the time of transection might develop new projections at metamorphosis. The possibility that the cells of origin of lumbar projections are born during the metamorphic period was investigated by injecting tadpoles with $\left[{ }^{3} \mathrm{H}\right]$ thymidine and then, after completion of metamorphosis, retrogradely labeling brainstem neurons by applying HRP to the lumbar enlargement. No double labeled brainstem neurons, which would indicate that newly born neurons give rise to lumbar projections, were found. In other experiments, HRP was applied to the lumbar spinal cord in tadpoles and, after metamorphosis, $\left[{ }^{3} \mathrm{H}\right]$ apo-HRP was applied to the same area. The numerous double labeled brainstem neurons found in these experiments provide assurance that descending connections are at least partially conserved through metamorphosis. These results are consistent with the hypothesis that true regeneration of at least some brainstem projections does occur; however, unequivocal demonstration of regeneration requires combining $\left[{ }^{3} \mathrm{H}\right]$ apo-HRP and HRP double labeling with intervening spinal cord transection and metamorphosis, an experiment that we have not yet been successful in completing.

The dramatic changes in body structure at metamorphosis and the behavioral demands of the new terrestrial environment require substantial alterations in the patterns of central nervous system connectivity. The processes that allow this reorganization also may allow correction of perturbations in connectivity resulting from the experimental lesion. The nature of these processes and the possibility of initiating their action experimentally remain questions for future study.

\section{References}

Afelt, Z. (1963) Variability of reflexes in chronic spinal frogs. In Central and Peripheral Mechanisms of Motor Function, E. Gutmann and P. Hnik, eds., pp. 37-41, Czechoslovak Academy of Science, Prague, Czechoslovakia.

Bernstein, J. J., and J. B. Gelderd (1970) Regeneration of the long spinal tracts in the goldfish. Brain Res. 20: 33-38.

Bernstein, J. J., and J. B. Gelderd (1973) Synaptic organization following regeneration of goldfish spinal cord. Exp. Neurol. 41: 402-410.

Borgens, R. B., E. Roederer, and M. J. Cohen (1981) Enhanced spinal cord regeneration in lamprey by applied electric fields. Science 213: 611-617.

Chu-Wang, I -W., R. W. Oppenheim, and P. B. Farel (1981) Ultrastructure of migrating spinal motoneurons in anuran larvae. Brain Res. 213: 307-318.

Cohen, A. H., and P. Wallen (1980) The neuronal correlate of locomotion in fish. "Fictive" swimming induced in an in vitro preparation of the lamprey spinal cord. Exp. Brain Res. 41: 11-18.

Cowan, W. M., D. I. Gottlieb, A. E. Hendrickson, and T. A. Woolsey (1972) The autoradiographic demonstration of axonal connections in the central nervous system. Brain Res. 37: 21-51.

Dickerson, M. C. (1969) The Frog Book, p. 234, Dover Publications, Inc., New York.

Farel, P. B. (1971) Long-lasting habituation in spinal frogs. Brain Res. 33: 405-417.

Farel, P. B., and S. E. Bemelmans (1980) Retrograde labeling of migrating spinal motoneurons in bullfrog larvae. Neurosci. Lett. 18: 133-136.

Forehand, C. J., and P. B. Farel (1980) Development of the anuran spinal cord: Ascending and descending systems. Soc. Neurosci. Abstr. 6: 847.

Forehand, C. J., and P. B. Farel (1981) Metamorphosis and descending input to lumbar spinal cord: An investigation using two retrograde tracers in Rana catesbeiana. Soc. Neurosci. Abstr. 7: 71.

Grillner, S. (1974) On the locomotion in the spinal dogfish. Exp. Brain Res. 20: 459-470. 
Hanker, J. S., P. E. Yates, C. B. Metz, and A. Rustioni (1977) A new specific, sensitive and non-carcinogenic reagent for the demonstration of horseradish peroxidase. Histochem. J. 9: 789-792.

Holtzer, H. (1952) Reconstitution of the urodele spinal cord following unilateral ablation. II. Regeneration of the longitudinal tracts and ectopic synaptic unions of the Mauthner's fibers. J. Exp. Zool. 119: 263-302.

Hooker, D. (1925) Studies on regeneration in the spinal cord. III. Reestablishment of anatomical and physiological continuity after transection in frog tadpoles. J. Comp. Neurol. 38: 315-347.

Hooker, D. (1932) Spinal cord regeneration in the young rainbow fish, Lebistes reticulatus. J. Comp. Neurol. 56: 227-297.

Lieberman, A. R. (1971) The axon reaction: A review of the principal features of perikaryal response to injury. Int. Rev. Neurobiol. 14: 49-124.

Michel, M. E., and P. J. Reier (1979) Axonal-ependymal associations during early regeneration of the transected spinal cord in Xenopus laevis tadpoles. J. Neurocytol. 8: 529-548.

Piatt, J. (1955) Regeneration in the central nervous system of amphibia. In Regeneration in the Central Nervous System, W. F. Windle, ed., pp. 20-46, Charles C Thomas, Springfield, IL.

Piatt, J., and M. Piatt (1958) 'Transection of the spinal cord in the adult frog. Anat. Rec. 131: 81-95.

Puchala, E., and W. F. Windle (1977) The possibility of structural and functional restitution after spinal cord injury: A review. Exp. Neurol. 55: 1-42.

Ramon y Cajal, S. (1959) Degeneration and Regeneration of the Nervous System, R. M. May, ed. and translator, Vol. II, pp. 482-516, Hafner, New York.

Rovainen, C. M. (1976) Regeneration of Muller and Mauthner axons after spinal transection in larval lampreys. J. Comp. Neurol. 168: 545-554.

Selzer, M. E. (1978) Mechanisms of functional recovery and regeneration after spinal cord transection in larval sea lamprey. J. Physiol. (Lond.) 227: 395-408.

Sims, R. T. (1962) Transection of the spinal cord in developing Xenopus laevis. J. Embryol. Exp. Morphol. 10: 115-126.

Soller, R. W. (1977) Monaminergic inputs to frog motoneurons: An anatomical study using fluorescence histochemical and silver degeneration techniques. Brain Res. 122: 445-458.

Stehouwer, D. J., and P. B. Farel (1980) Central and peripheral controls of swimming in anuran larvae. Brain Res. 195: 323-335.

Stehouwer, D. J., and P. B. Farel (1981) Sensory interactions with a central motor program. Brain Res. 218: 131-140.

Taylor, A. C., and J. J. Kollros (1946) Stages in the normal development of Rana pipiens. Anat. Rec. 94: 7-24.

Tuge, H., and S. Hanzawa (1937) Physiological and morphological regeneration of the sectioned spinal cord in adult teleosts. J. Comp. Neurol. 67: 343-365.

Wood, M. R., and M. J. Cohen (1979) Synaptic regeneration in identified neurons of the lamprey spinal cord. Science 206: 344-347.

Wood, M. R., and M. J. Cohen (1981) Synaptic regeneration and glial reactions in the transected spinal cord of the lamprey. J. Neurocytol. 10: 57-79. 